\title{
BMJ Open Goal-directed versus outcome-based financial incentives for weight loss among low-income patients with obesity: rationale and design of the Financial Incentives foR Weight Reduction (FIReWoRk) randomised controlled trial
}

\author{
Melanie Jay, ${ }^{1}$ Stephanie L Orstad, ${ }^{\circ 2}$ Soma Wali, ${ }^{3}$ Judith Wylie-Rosett, ${ }^{4}$ \\ Chi-Hong Tseng, ${ }^{5}$ Victoria Sweat, ${ }^{2}$ Sandra Wittleder, ${ }^{2}$ Suzanne B Shu, ${ }^{6}$ \\ Noah J Goldstein, ${ }^{6}$ Joseph A Ladapo ${ }^{5}$
}

To cite: Jay M, Orstad SL, Wali S, et al. Goal-directed versus outcome-based financial incentives for weight loss among low-income patients with obesity: rationale and design of the Financial Incentives foR Weight Reduction (FIReWoRk) randomised controlled trial. BMJ Open 2019;9:e025278. doi:10.1136/ bmjopen-2018-025278

- Prepublication history for this paper is available online To view these files, please visit the journal online (http://dx.doi org/10.1136/bmjopen-2018025278).

MJ and SLO contributed equally.

Received 13 July 2018

Revised 23 January 2019

Accepted 12 February 2019

Check for updates

(c) Author(s) (or their employer(s)) 2019. Re-use permitted under CC BY-NC. No commercial re-use. See rights and permissions. Published by BMJ.

For numbered affiliations see end of article.

Correspondence to

Dr Joseph A Ladapo;

jladapo@mednet.ucla.edu

\section{ABSTRACT}

Introduction Obesity is a major public health challenge and exacerbates economic disparities through employment discrimination and increased personal health expenditures. Financial incentives for weight management may intensify individuals' utilisation of evidence-based behavioural strategies while addressing obesity-related economic disparities in low-income populations. Trials have focused on testing incentives contingent on achieving weight loss outcomes. However, based on social cognitive and selfdetermination theories, providing incentives for achieving intermediate behavioural goals may be more sustainable than incentivising outcomes if they enhance an individual's skills and self-efficacy for maintaining long-term weight loss. The objective of this paper is to describe the rationale and design of the Financial Incentives foR Weight Reduction study, a randomised controlled trial to test the comparative effectiveness and cost-effectiveness of two financial incentive strategies for weight loss (goal directed vs outcome based) among low-income adults with obesity, as well as compared with the provision of health behaviour change resources alone.

Methods and analysis We are recruiting 795 adults, aged $18-70$ years with a body mass index $\geq 30 \mathrm{~kg} /$ $\mathrm{m}^{2}$, from three primary care clinics serving residents of socioeconomically disadvantaged neighbourhoods in New York City and Los Angeles. All participants receive a 1-year commercial weight loss programme membership, self-monitoring tools (bathroom scale, food journal and Fitbit Alta HR), health education and monthly check-in visits. In addition to these resources, those in the two intervention groups can earn up to $\$ 750$ over 6 months for: (1) participating in an intensive weight management programme, self-monitoring weight and diet and meeting physical activity guidelines (goal-directed arm); or (2) a $\geq 1.5 \%$ to $\geq 5 \%$ reduction in baseline weight (outcomebased arm). To maximise incentive efficacy, we incorporate concepts from behavioural economics, including
Strengths and limitations of this study

This three-arm randomised controlled trial compares the impact of two financial incentives strategies on a $\geq 5 \%$ reduction in body weight at 6 months among primary care patients from socioeconomically disadvantaged neighbourhoods.

- Comparing goal-directed versus outcome-based financial incentives is important because it directly addresses outstanding questions about how to structure financial incentive interventions optimally.

- The intervention design leverages principles of behavioural economics to connect patients with existing clinic and community resources and intensify utilisation of evidence-based behavioural strategies for weight loss.

- Patients in all three arms receive substantial resources, including weight loss programme membership, bathroom scale, food journal, Fitbit Alta HR and monthly in-person visits, which may reduce our ability to detect the marginal value of the financial incentives.

- We anticipate that the results will inform the design of scalable financial incentive programmes to address obesity in public and private health systems.

immediacy of payments and framing feedback to elicit regret aversion. We will use generalised mixed effect models for repeated measures to examine intervention effects on weight at 6, 9 and 12 months.

Ethics and dissemination Human research protection committees at New York University School of Medicine, University of California Los Angeles (UCLA) David Geffen School of Medicine and Olive-View-UCLA Medical Center granted ethics approval. We will disseminate the results 
of this research via peer-reviewed publications, conference presentations and meetings with stakeholders.

Trial registration number NCT03157713.

\section{INTRODUCTION}

The prevalence of obesity among US adults is $40 \%$ and continues to rise, contributing substantially to morbidity and mortality from obesity-related illnesses such as diabetes, heart disease, stroke and cancer. ${ }^{1-3}$ Obesity prevalence among UK adults is $26 \%$, the highest of European countries. ${ }^{45}$ Obesity is more prevalent among adults with a lower socioeconomic status. ${ }^{6}$ Because individuals with obesity also face social stigma, including employment discrimination and bias in educational settings, ${ }^{7}$ the increased prevalence of obesity among lower income individuals exacerbates health and socioeconomic disparities. Moreover, the negative externalities of obesity include an attributable annual US healthcare cost of $\$ 147$ billion, including services provided by both public and private payers for inpatient care, non-inpatient care and prescription drugs. ${ }^{8}$ The UK National Health Service spent an estimated $£ 6.1$ billion on overweight and obesity-related illness in 2014-2015, with societal costs estimated at $£ 27$ billion. ${ }^{9}$

The US Preventive Services Task Force (USPSTF) recommends universal obesity screening in healthcare settings and intensive, multicomponent behavioural interventions for adults with obesity. ${ }^{10} 11$ However, national data show that physicians often do not provide nutrition, exercise or weight loss counselling for patients with obesity. ${ }^{12}$ Moreover, $51 \%$ of US adults report wanting to lose weight, but only half are actively trying, and an even smaller proportion use evidence-based methods. ${ }^{12-15} \mathrm{~A}$ reduction in weight of as little as $5 \%$ is associated with cardiovascular health benefits. ${ }^{16-18}$ It is therefore critical to identify novel approaches to increase utilisation of effective, evidence-based behaviour change strategies and weight management programmes (eg, Weight Watchers, the Diabetes Prevention Program and the Veterans Affairs MOVE! Program ${ }^{19-21}$ ) to promote weight loss and improve health outcomes, particularly among socioeconomically disadvantaged individuals. Financial incentives are a potential bridge to increasing utilisation of effective weight management behaviours and programmes among low-income adults with obesity. ${ }^{22}$

Health insurers, employers and government agencies are testing the extent to which financial incentive strategies motivate changes in health behaviour, particularly for obesity and smoking. ${ }^{23} 24$ Microeconomic theory suggests that financial incentives lead to weight loss because individuals are influenced by the prospect of rewards. This effect may be enhanced when the incentive design emphasises immediacy (payments provided as soon as possible), so that individuals can more readily associate a payment with the behaviour that triggered it, ${ }^{25} 26$ and regret aversion (avoidance of regret from losing an anticipated reward). ${ }^{27}$ While some theories of motivation have led researchers to raise concerns about the longterm durability of the extrinsic effects of incentives, ${ }^{29}$ studies have shown that incentives may promote intermediate-to-long-term weight loss. ${ }^{29-37}$ Despite these findings, a key unanswered question is what targets to incentivise. ${ }^{38}$

Incentivising an individual's participation in goal-directed, evidence-based behaviours for weight loss, such as participating in a weight management programme, self-monitoring weight and diet and achieving physical activity goals, may be more sustainable than incentivising outcome-based attainment of weight loss, since goal-directed financial incentives are designed to encourage individuals to develop specific skills for maintaining weight loss long term. In addition, attainment of behavioural goals precedes weight loss outcomes, thereby providing earlier opportunities for success, which may increase self-efficacy and intrinsic motivation for weight management. ${ }^{39}$ Based on social cognitive theory, ${ }^{40}$ incentivising behavioural practice directly may help patients build the self-efficacy to engage in evidence-based strategies and maintain these behaviours even after an incentive is removed. Self-determination theory ${ }^{41}$ highlights the role that intrinsic motivation may play in an individual's sustained behaviour change, since engaging in a strategy he or she has mastered can provide satisfaction and enjoyment (figure 1).

To date, financial incentive interventions for weight loss have favoured outcome-based over goal-directed incentive designs. In general, outcome-based designs have been shown to promote weight loss during the intervention period, though few studies have resulted in significant long-term weight loss, when this outcome was measured. ${ }^{42-44}$ For example, in a 32-week trial among Veterans with obesity, net weight loss between the incentive and control groups was no longer significant 36 weeks postintervention. ${ }^{45}$ Based on social cognitive and self-determination theories described above, goal-directed incentives may promote short-term weight maintenance. Even if goal-directed incentives do not sustain weight loss, they likely are more effective than outcome-based incentives at promoting health behaviours, such as physical activity, ${ }^{46}$ that are associated with decreased morbidity and mortality.

Further research is needed to test whether the effectiveness of financial incentives for weight loss that incorporate immediacy and regret aversion can be maximised by targeting utilisation of effective weight management behaviours and programmes. Studies are also needed to assess the economic sustainability of financial incentives, which is a major factor in public and private decision making. ${ }^{47}$ The primary aim of the Financial Incentives foR Weight Reduction (FIReWoRk) study is to compare the effectiveness of goal-directed versus outcome-based financial incentives on $\geq 5 \%$ wt loss among patients with obesity living in socioeconomically disadvantaged neighbourhoods, as well as compared with the provision of health behaviour change resources alone. Financial Incentives foR Weight Reduction (FIReWoRk) also examines the impact of these interventions on patients' use 


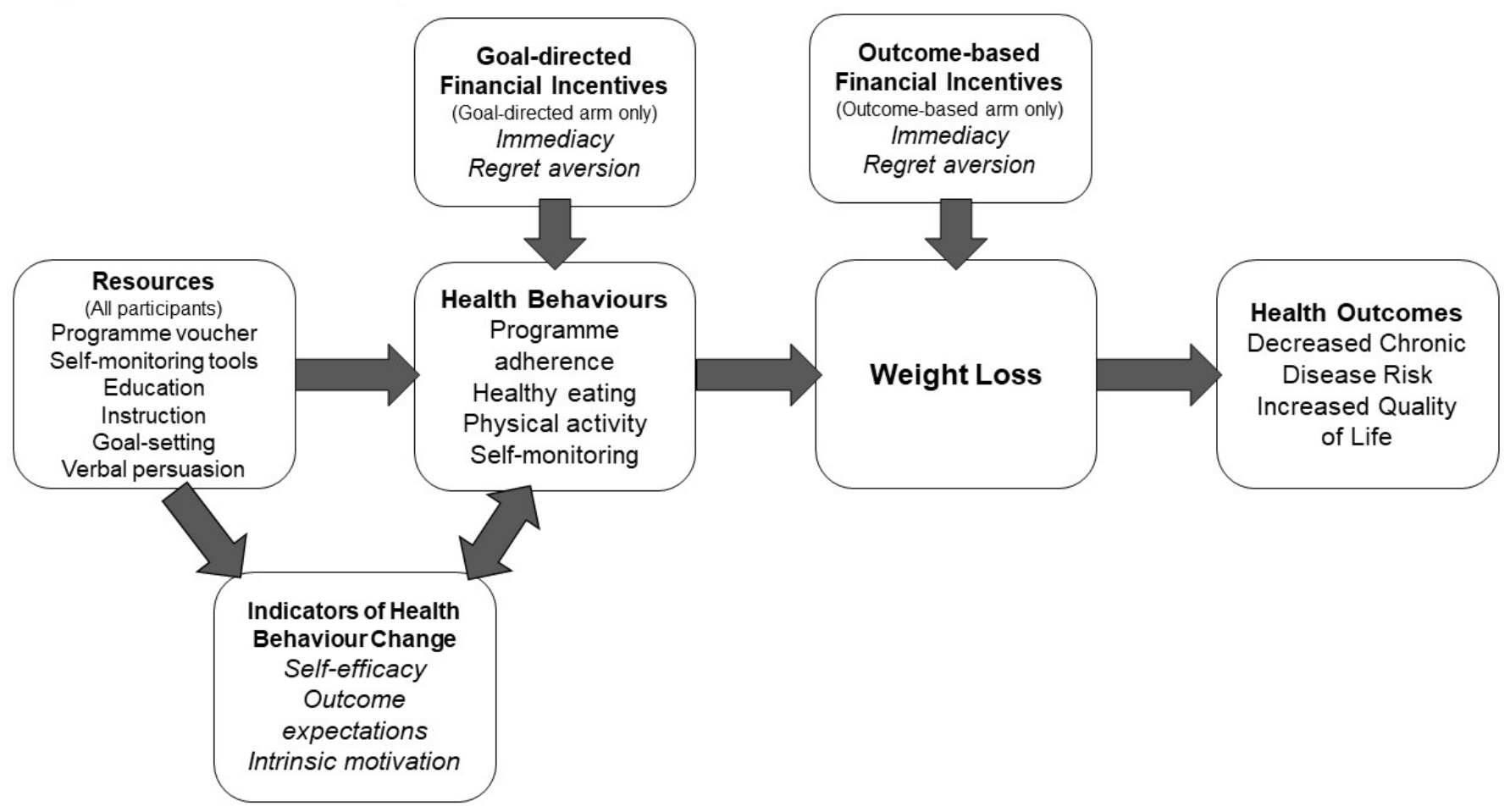

Figure 1 FIReWoRk conceptual model. FIReWoRk, Financial Incentives foR Weight Reduction.

of evidence-based weight management programmes, waist circumference, blood pressure and quality of life. A secondary aim is to examine the cost-effectiveness of using goal-directed incentives to promote weight loss as compared with outcome-based incentives or resources without incentives. The purpose of this paper is to describe the rationale and design of the FIReWoRk study.

\section{METHODS AND ANALYSES}

\section{Study overview and design}

The FIReWoRk study is a three-arm randomised controlled trial to compare the effectiveness of three approaches to weight loss among primary care patients with obesity. Patients usually achieve maximum weight loss during the first 6 months of a behavioural intervention. ${ }^{48}$ Thus, our primary outcome is a $\geq 5 \%$ reduction in baseline weight at 6 months. Our primary hypothesis is that a greater proportion of participants in the goal-directed incentives arm will obtain a $\geq 5 \%$ reduction in baseline weight at 6 months than in the outcome-based incentives arm or the resources-only arm. Our secondary hypothesis is that a greater proportion of participants in the goal-directed arm will maintain a $\geq 5 \%$ reduction in baseline weight at 12 months than in the outcome-based arm or the resources-only arm. We are enrolling adults living in socioeconomically disadvantaged neighbourhoods from three medical centres that serve predominately low-income populations. Participants in all three study arms receive a 1 year commercial weight loss programme membership, self-monitoring tools (bathroom scale, food journal and Fitbit Alta HR), health education and monthly, in-clinic check-in visits. In addition, participants in the outcomebased incentives arm can earn up to $\$ 750$ over 6 months for a $1.5 \%-5 \%$ reduction in baseline weight, while those in the goal-directed incentive arm can earn the same amount for engaging in the following evidence-based weight loss behaviours: weight management programme participation, self-monitoring weight and diet, and physical activity.

\section{Primary care clinics and patients}

We are recruiting patients exclusively from three primary care clinics in New York City (NYC) and Los Angeles (LA), with plans to enrol 795 adults with obesity from low-income neighbourhoods. The clinics are part of NYC Health+Hospitals - Bellevue, Sunset Park Family Health Center at NYU Langone Hospital - Brooklyn and Olive View UCLA Medical Center. Bellevue Hospital is the flagship hospital for the largest public health care system in the nation. There are approximately 60000 outpatient visits in Bellevue's adult primary care clinic each year. Family Health Centers at NYU Langone is one of the largest Federally Qualified Health Center networks in the nation. Its network of eight primary care and specialty sites handles over 600000 visits annually. Olive View UCLA Medical Center is operated by the LA County Department of Health Services, which supports a network of hospitals and primary care clinics in and around the LA metro area. More than half of Olive View patients are underinsured or uninsured. All locations serve racially/ ethnically diverse, medically underserved populations in which the prevalence of obesity is above the national average. 
Each of these hospitals uses an electronic health record (EHR) system that captures detailed inpatient and outpatient information. We conduct EHR queries every 6 months to identify patients with obesity who have seen a provider in the previous 2 years. To identify patients with obesity who live in socioeconomically disadvantaged neighbourhoods, we cross-reference patients' address information from their EHR with census tracts associated with the lowest $40 \%$ of 2015 median household income in the NYC/Tri-State and LA County areas (approximately $<\$ 40000$ per year) ${ }^{49}$ Because we are recruiting from neighbourhoods with a higher proportion of minority residents and from low-income census tracts, we anticipate that our sample will have a higher proportion of ethnic and racial minorities, particularly Hispanic/Latinos than is reflected in the general population. We approach recruitment in ways shown previously to potentially reduce burden and enhance trust among prospective participants who are racial/ethnic minorities and live in low-income neighbourhoods. ${ }^{50}{ }^{51}$ Examples include recruiting from racial/ethnic minority-serving medical centres, hiring English-Spanish bilingual and racially/ethnically diverse research staff, providing information about the study in the patient's native language, compensating participants for completing study visits and collecting contact information for at least one relative or friend.

As a primary recruitment method, we mail announcements about the study to the homes of patients identified via the EHR and neighbourhood queries and invite them to contact us. We follow-up with patients by phone, beginning when we expect the mailing to arrive and continuing until completing four outreach attempts. We also identify upcoming primary care appointments of patients identified via the queries, at which time we approach them in waiting rooms with information about the study. We schedule interested patients who pass an eligibility screening for a baseline visit at or near their home medical centre within 1 month of their screening date. No more than one person per household is eligible to participate. As secondary recruitment methods, we communicate with primary care physicians and medical residents at the study sites who may be willing to refer their patients to the study. There is also a physician within each clinic willing to 'champion' the study by reminding providers to refer their patients, answering questions and providing study updates. We regularly post recruitment flyers and brochures in areas of the clinic frequented by patients.

\section{Sample size}

Prior studies suggest that among patients with obesity, the prevalence of obtaining a $5 \%$ reduction in baseline weight by 6 months is $10 \%-35 \% .^{52-55}$ Thus, we assume an absolute difference $\left(\right.$ rate $_{2}-$ rate $_{1}$ ) of approximately 10 percentage points in rates of obtaining a $5 \%$ reduction in baseline weight by 6 months between the two incentives arms $(24 \%$ and $14 \%$ of participants obtaining a $5 \% \mathrm{wt}$ reduction in the goal-directed and outcome-based intervention arms, respectively). Therefore, 241 participants per group provides at least $80 \%$ power to detect a meaningful difference in weight loss between the goal-directed and outcome-based intervention arms with a type I error rate $\alpha=0.05$. It also provides at least $99 \%$ power to detect a meaningful difference in weight loss between the goal-directed incentives and resources-only arms $(24 \%$ and $10 \%$ of participants obtaining a $5 \%$ wt reduction in the goal-directed incentives and resources-only arms, respectively) with a type I error rate $\alpha=0.05$. Since there is only one primary hypothesis, there is no multiple comparison adjustment in the sample size calculation. We also assume a 6-month loss-to-follow-up rate of $10 \%$; therefore, we will enrol an additional 72 patients for a total sample size of 795.

\section{Eligibility and enrolment}

We include patients with a body mass index $\geq 30 \mathrm{~kg} / \mathrm{m}^{2}$, who are 18-70 years old, speak English or Spanish, have seen their physician within the past 2 years, have an active US mobile or home phone number and address and live in a qualifying census tract. Patients who weigh $>172 \mathrm{~kg}$ are not enrolled, as the HealthOMeter 349KLX Digital Medical Weight Scale is only valid up to $181 \mathrm{~kg}$ and we allow for a 9-kg buffer in case weight gain occurs. We exclude patients who have had a weight loss surgery or procedure in the previous 2 years or have experienced any of the following in the previous 6 months: $\geq 4.5 \mathrm{~kg}$ weight loss, completion of an intensive weight management programme, active psychosis and/or other cognitive issues, metastatic cancer or incidence of a myocardial infarction or stroke. We also exclude patients who report abuse of alcohol, have a history of disordered eating, have stage $\mathrm{V}$ chronic kidney disease or end-stage renal disease, are pregnant or breast feeding, plan to become pregnant or plan to move out of NYC/Tri-State or LA County area in the following 12 months.

Once screened by phone, we invite eligible patients to a baseline study visit at their home medical centre and obtain informed consent. To provide informed consent, we: (1) describe the study and its risks and benefits in detail from a script tested for eighth grade reading comprehension, (2) assess comprehension by asking the patient to explain the information presented (teach-back method $^{56}$ ), (3) answer questions about the study and/ or consent forms, (4) offer the opportunity to participate and (5) obtain the patient's signature on the consent form. ${ }^{57}$ The participant receives a copy of the signed consent form by email.

\section{Randomisation}

Randomisation occurs after obtaining informed consent, completing initial weight measures, administering the baseline survey instrument and providing weight management programme referrals, health education materials and self-monitoring tools. Participants are randomised to one of three study arms: (1) outcome-based incentives, (2) 


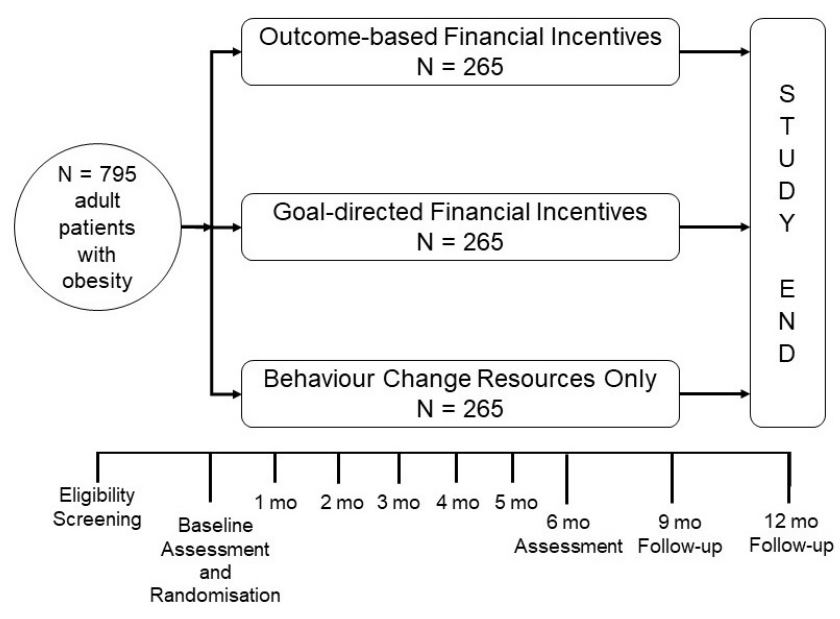

Figure 2 Patient randomisation to study groups.

goal-directed incentives or (3) resources only (figure 2). To ensure comparable group sample sizes, we randomise eligible patients in block sizes of four or six at random using a random number generator in $\mathrm{R}$ (www.r-project. org). We stratify randomisation by study site and participant's self-reported preference for an outcome-based or goal-directed financial incentive programme for weight loss in order to ensure that both intervention groups contain an equal number of participants preferring each incentive type. Stratified randomisation also prevents imbalance between treatment groups by hospital site.

\section{Financial incentives intervention for weight loss}

Interventionists: trained research coordinators or research assistants (RAs) conduct all study visits. RAs are students or graduates of health-related disciplines such as biomedicine, public health, health promotion, education, psychology, kinesiology and nutrition. To promote enrolment of Spanish-speaking patients, RAs are required to have full native or professional Spanish proficiency. RAs receive at least 20 hours of standardised training in the responsible conduct of research, study protocols and cultural sensitivity. RAs observe and role play a series of study visits in both English and Spanish and can successfully demonstrate intervention delivery before conducting study visits.

Baseline study visit: at a 2.5-hour initial study visit, all participants receive a list of local weight management programmes that meet criteria for a high-intensity, on-site, multicomponent lifestyle intervention ${ }^{58}$ and a voucher for 1 year of WW Freestyle (formerly Weight Watchers) membership (total value approximately US\$310). ${ }^{20}$ Participants can choose to attend a commercial, medical or community-based weight management programme that is offered at least twice monthly and meets guidelines for an intensive comprehensive lifestyle intervention. ${ }^{58}$ The RA communicates that the goal is for the participant to register and actively participate in at least $50 \%$ of weekly programme sessions per month (or a comparable rate associated with evidence-based weight loss). All participants also receive self-monitoring instructions and tools ${ }^{59-61}$ including a bathroom scale, a BookFactory food journal and a Fitbit Alta HR wearable fitness tracker (total value approximately US\$170). ${ }^{62}$ The RA communicates that the goals are for the participant to weigh themselves at least 3 days per week, to record what and how much they eat at least 5 days per week and accumulate at least 75 physical activity minutes per week (which increases to 150 min per week after 3 months to approximate physical activity guidelines ${ }^{63}$ ). The behavioural science construct of emergency reserves informs how the RA frames the goals; for example, the RA encourages the participant to "track what you eat every day, but you have two emergency "skip days" per week if you fall behind'. Goals with emergency reserves are perceived as more attainable and lead to increased goal persistence. ${ }^{64}$ The RA also communicates that the participant is to lose $\geq 2.5 \%$ of their baseline weight by 1 month and $\geq 5 \%$ by 2 months and provides their weight in pounds for each target. The RA communicates each behavioural goal and weight loss outcome both verbally and in writing, and then asks for the participant's understanding using the teach-back method. ${ }^{56}$ The RA also discusses how to prevent relapse. ${ }^{59}$ The RA then explains what documentation participants must provide to verify their goal attainment at subsequent study visits. In addition, participants receive health education and handouts on food types to incorporate and which to limit, portion sizes, healthy recipe ideas and moderate-intensity physical activity. The RA also assists the participant in setting up their Fitbit device and online Fitbit and WW Freestyle accounts so that they can access the features available through their smartphone or computer.

Outcome-based incentives: if a participant is randomised to an intervention arm, the RA informs them of the behavioural goals or weight loss outcomes for which they earn incentives, the amounts they are incentivised and how they receive their payments. Participants randomised to receive outcome-based incentives can earn up to $\$ 750$ over 6 months for losing $\geq 1.5 \%$ to $\geq 5 \%$ of their baseline weight, as confirmed at monthly weigh-ins. At 1 month, they receive $\$ 50$ if they lose $\geq 1.5 \%$ to $<2.5 \%$ or $\$ 100$ if they lose $\geq 2.5 \%$. The weight loss outcomes at 1 month are more modest to discourage overly rapid weight loss. At 2 and 3 months, they receive $\$ 50$ if they lose $\geq 2.5 \%$ to $<5 \%$ or $\$ 100$ if they lose $\geq 5 \%$ of their baseline weight. At 4,5 and 6 months, they receive $\$ 100$ if they lose $\geq 2.5 \%$ to $<5 \%$ or $\$ 150$ if they lose $\geq 5 \%$ of their baseline weight (table 1). The maximum value of each incentive intervention is approximately US $\$ 1230$ (US $\$ 750$ plus the US $\$ 480$ financial value of the control intervention).

Goal-directed incentives: participants randomised to goal-directed incentives do not earn money for losing weight but instead earn up to $\$ 750$ over 6 months for meeting goals to participate in an approved comprehensive lifestyle intervention, meet physical activity guidelines and self-monitor weight and diet. At 1-6 months, they receive a one-time $\$ 150$ for registration and attendance at $\geq 50 \%$ of weekly weight management programme 
Table 1 Financial incentives awarded for meeting monthly behavioural goals and weight loss outcomes

\begin{tabular}{|c|c|c|c|}
\hline & Time point & $\begin{array}{l}\text { Goal-directed } \\
\text { incentives* }\end{array}$ & $\begin{array}{l}\text { Outcome-based } \\
\text { incentives }\end{array}$ \\
\hline \multicolumn{4}{|l|}{ Behavioural goals } \\
\hline $\begin{array}{l}\text { Active participation† in an evidence-based } \neq \\
\text { weight management programme }\end{array}$ & $2,3,4,5$ and 6 months & $\$ 60$ & $\$ 0$ \\
\hline Achievement of $\geq 75$ min of physical activity per week & 1,2 and 3 months & $\$ 20$ & $\$ 0$ \\
\hline Achievement of $\geq 150$ min of physical activity per week $\emptyset$ & 4,5 and 6 months & $\$ 20$ & $\$ 0$ \\
\hline Self-weighing ${ }^{\star *}$ & $1,2,3,4,5$ and 6 months & $\$ 10$ & $\$ 0$ \\
\hline \multicolumn{4}{|l|}{ Weight loss outcomes } \\
\hline Total incentives (maximum) & & $\$ 750$ & $\$ 750$ \\
\hline
\end{tabular}

*Incentive is proportional to the number of weeks in the previous 28 days this goal is met (eg, incentive may range from $\$ 5$ for 1 week to $\$ 20$ for 4 weeks).

†Attending $\geq 2$ sessions per month or $\geq 50 \%$ of sessions monthly, whichever is greater.

$\ddagger$ Programme participation goal is based on established American Heart Association/American College of Cardiology/The Obesity Society guidelines for the management of overweight and obesity in adults.

$\S$ Recording diet content and quantity $\geq 5$ days per week.

ๆPhysical activity goal is based on established public health guidelines for moderate-vigorous intensity physical activity in adults.

${ }^{* *}$ Recording weight $\geq 3$ days per week.

†† $\$ 50$ for losing $\geq 1.5 \%$ to $<2.5 \%$ and $\$ 100$ for losing $\geq 2.5 \%$ of baseline weight.

$\ddagger \ddagger \$ 50$ for losing $\geq 2.5 \%$ to $<5 \%$ and $\$ 100$ for losing $\geq 5 \%$ of baseline weight.

$\S \S \$ 100$ for losing $\geq 2.5 \%$ to $<5 \%$ and $\$ 150$ for losing $\geq 5 \%$ of baseline weight.

sessions, as verified with documentation from the sessions such as an agenda or weight log or by a record of attendance in the participant's EHR, if available. They continue to receive $\$ 60$ monthly thereafter for attendance at $\geq 50 \%$ of weekly programme sessions (or a comparable rate associated with evidence-based weight loss). At 1-3 months, they receive up to $\$ 20$ for achieving $75 \mathrm{~min}$ of physical activity per week ( $\$ 5$ per week), as verified using active minutes data collected in the participant's Fitbit account. At 4-6 months, they must achieve $150 \mathrm{~min}$ of physical activity per week to receive up to $\$ 20$. At $1-6$ months, they receive up to $\$ 20$ for using their food journal 5 days per week (\$5 per week) and recording their body weight 3 days per week ( $\$ 2.50$ per week), as verified by RA review of their entries (table 1). Participants receive incentives for multiple behaviours and strategies because of the necessity of a multicomponent approach for successful weight management. One drawback of this approach is that we may be unable to determine the relative impact of each behaviour and strategy on weight loss. Incentives are highest for participation in a comprehensive lifestyle intervention such as WW Freestyle because attendance in such programmes has been shown to lead to clinically significant weight loss, ${ }^{1158}$ as has engaging in physical activity and self-monitoring diet and weight (considered markers of engagement in WW Freestyle). However, we recognise not everyone can or will participate in a programme. Thus, participants also receive incentives for engaging in evidence-based weight management behaviours and strategies outside of an approved programme.

Check-in study visits: in-clinic check-in visits occur monthly at 1-6 months, proceeded by follow-up visits at 9 and 12 months. During check-in visits, RAs measure weight and waist circumference. The RA also troubleshoots any technology-related issues that arise with the participant's Fitbit or WW Freestyle membership. The majority of the $30-45 \mathrm{~min}$ visit is devoted to verifying whether participants met their behavioural goals and weight loss outcome and providing them with feedback on their progress. For the resources-only group, the RA provides words of encouragement for meeting a behavioural goal or weight loss outcome (eg, 'Great job!'). If the participant did not meet a goal or outcome, the RA states, 'if you had done $\mathrm{x}$, you would have met this goal'. For the goal-directed and outcome-based groups, the RA provides words of encouragement for meeting a behavioural goal or weight loss outcome and informs them of incentive amounts earned. If the participant did not meet a goal or outcome, the RA states, "if you had done $\mathrm{x}$, you could have earned $\mathrm{x}$ amount', using framing that leverages regret aversion. We considered using more frequent (eg, weekly) incentive payments; however, we opted to minimise the participant 
burden of weekly in-person or remote weigh-ins to verify goal attainment and adhere to an intensity (ie, monthly) more translatable to a real-world setting. After the RA verifies the participant's goal attainment, the RA communicates the incentive amount earned but does not provide payment during the visit. Immediately after the visit, the RA initiates payment via a secure prepaid debit card system called ClinCard (2016 Greenphire). Incentives are available to participants via their ClinCard within 24-48 hours after goal verification. We inform participants during the consenting process that if they earn US\$600 or more in a calendar year, they will receive the appropriate tax form to report their income as well as compensation to offset any tax liability. Participants do not invest any of their own money at any time, nor do the incentives incorporate a lottery structure.

\section{Intervention standardisation and fidelity}

We implement fidelity monitoring procedures to ensure that the delivery of intervention components is standard across all study sites and RAs. All RAs complete a task list at each study visit. A portion of study visits are audio-recorded, and recorded sessions are randomly selected for audit using a fidelity-monitoring checklist. RAs who score less than $80 \%$ on an audit receive remedial training and are required to demonstrate the unattained standard prior to resuming study visits. ${ }^{65}$

\section{Participant retention strategies}

At the end of each check-in visit, RAs schedule participants for their next visit and place a text message within 7 days and a phone call within 2 days prior to their scheduled visit to encourage them to return. To increase participation and minimise attrition, all participants receive a total payment for participation of up to US $\$ 180$ ( $\$ 20$ per visit) for their time and travel, independent of incentives earned in the intervention groups. We also provide participants with periodic tokens of appreciation, including a button with the study logo after their 3-month visit and a thank you text message after their 6-month and 9-month visits. ${ }^{50}$ In addition, we conduct a process evaluation to explore differences in participant retention and uptake of intervention components (eg, self-weighing and Fitbit wear) by study arm, hospital site and prespecified subgroups (women, Black and Hispanic). We also explore participants' experiences interacting with the intervention components using a semistructured interview at 6 months. The process evaluation allows us to assess reasons the intervention may or may not have the intended effects and to improve the acceptability of future interventions. If participants do not return for their check-in visits, we attempt to contact them by phone to assess their reasons for leaving the study.

\section{Data collection and measures}

Assessments occur at baseline, 30 days and 2, 3, 4, 5, 6, 9 and 12 months (table 2). Our primary outcome is the percentage of patients who achieve a $>5 \%$ reduction in baseline weight at 6 months, an amount considered clinically significant for overweight/obese adults because of its associated reductions in cardiometabolic risk. ${ }^{16} 17$ We also will assess the percentage of patients who maintain a $>5 \%$ reduction in baseline weight at 6 months and compare mean weight loss achieved in each group at 6 months and 12 months. Our secondary outcomes include weight management programme attendance, waist circumference, blood pressure and quality of life. At baseline, we confirm contact information; collect demographic characteristics; measure height, weight and blood pressure; take a brief medical history; and administer survey instruments about diet composition, physical activity, theoretical mechanisms of health behaviour change, financial well-being and quality of life. The survey is interviewer administered in the participant's preferred language (English or Spanish). Participants are assured there are 'no right or wrong answers' and to 'answer as honestly as possible'. At 1-6month check-in visits, we assess adherence to a weight management programme, self-monitoring of weight and diet and physical activity. We administer weight, blood pressure and the survey instruments again at 6 months (primary outcome time point), 9 months and 12 months. At 6, 9 and 12 months, we also ask participants about hospitalisations and emergency room visits and use of medications that may modify weight (eg, metformin, insulin, antidepressants and so on). ${ }^{66}$ Whenever possible at 6,9 and 12 months, an RA who has not met regularly with the participant and who is unaware of their study arm assignment administers the biometric assessments and survey interviews and enters the results into REDCap 7.4.23, a secure web-based application. All biometric procedures are adapted from the National Health and Nutrition Examination Survey (NHANES) ${ }^{67}$ and survey measures are selected based on their validity against an established criterion, and validation with Spanish-speaking adults, when available.

Weight and height: weight is measured in pounds twice to the nearest 0.1 pound using a HealthOMeter 349KLX Digital Medical Weight Scale. We ask the participant to remove shoes and heavy garments and to stand still with both feet in the centre of the scale, hands at sides, looking straight ahead. If the first two weights differ by 0.5 pound or more, we repeat the measure once and take the average of the two measures closest in value. Height is measured once, rounded up to the nearest $0.1 \mathrm{~cm}$, using a SECA 213 Portable Stadiometer. We ask the participant to remove shoes and extraneous clothing and undo interfering hairstyles, then to stand upright looking straight ahead with heels, buttocks, shoulder blades and back of head positioned against the ruler.

Waist circumference: waist circumference is measured twice, rounding down to the nearest 0.25 inch. We take the measurement on bare skin if possible, at the high point of the iliac crests, drawing the tape measure snug at minimal respiration. If the first two values differ by 0.5 inch or more, we repeat the measure once, and take the average of the two measures closest in value. 
Table 2 Study measures and assessment time points

\begin{tabular}{|c|c|c|c|c|}
\hline Measure & Baseline & 1-5 months & 6 and 9 months & 12 months \\
\hline \multicolumn{5}{|l|}{ Survey measures } \\
\hline Sociodemographics & $\mathrm{x}$ & & & \\
\hline Incentives preferences & $\mathrm{X}$ & & & \\
\hline Quality of life & $x$ & & $x$ & $x$ \\
\hline Fruits and vegetables & $\mathrm{X}$ & & $x$ & $x$ \\
\hline Sweets and salty snacks & $X$ & & $x$ & $\mathrm{x}$ \\
\hline Sugar-sweetened beverages & $x$ & & $x$ & $x$ \\
\hline Physical activity & $\mathrm{x}$ & & $\mathrm{x}$ & $\mathrm{x}$ \\
\hline Self-efficacy & $x$ & & $x$ & $x$ \\
\hline Financial well-being & $x$ & & $x$ & $\mathrm{x}$ \\
\hline Weight loss programme attendance & & $x$ & $x$ & $x$ \\
\hline Self-monitoring & $x$ & $x$ & $x$ & $x$ \\
\hline Alcohol and tobacco use & $x$ & & & $x$ \\
\hline $\begin{array}{l}\text { Hospitalisations and emergency room } \\
\text { visits }\end{array}$ & & & $\mathrm{x}$ & $x$ \\
\hline Adverse events & & $x$ & $x$ & $x$ \\
\hline \multicolumn{5}{|l|}{ Other measures } \\
\hline Height & $x$ & & & \\
\hline
\end{tabular}

Blood pressure: two resting blood pressure measures are obtained using the Omron HEM 907XL IntelliSense Professional Digital Blood Pressure Monitor, an automated sphygmomanometer. The participant remains seated without consuming caffeine or nicotine for $30 \mathrm{~min}$ prior to the measurement. We measure arm circumference first to determine the appropriate cuff size, then place the cuff snugly on the left upper arm with the bottom of the cuff approximately $2.5 \mathrm{~cm}$ above the inner elbow. The arm rests palm-up at heart level, and the participant remains silent and still, with both feet on the floor, during the measurement. ${ }^{68}$ If the first two systolic or diastolic values differ by $5.0 \mathrm{~mm} \mathrm{Hg}$ or more, we remove and adjust the cuff, repeat the two measures and take the average of the subsequent two measures that do not differ by $5.0 \mathrm{~mm} \mathrm{Hg}$ or more.

Lipids and haemoglobin A1c: fasting lipids (high-density and low-density lipoprotein cholesterol, triglycerides and total cholesterol) and haemoglobin A1c values from a 12-month period prior to baseline are accessed via the participant's EHR. Since these tests are clinically indicated for patients with obesity, we also recommend that they obtain them at the conclusion of the 6-month intervention period. We access available values a second time from a 12-month period following the conclusion of the 6-month intervention period.

Quality of life: the 29-item Patient-Reported Outcomes Measurement Information System (PROMIS-29) is used to assess physical, mental and social health. ${ }^{69}$ The PROMIS-29 measures eight domains (fatigue, pain intensity, pain interference, physical function, sleep disturbance, anxiety, depression and ability to participate in social roles and activities) and yields a composite global health score. The PROMIS-29 is applicable to the general population, as well as to ethnically and sociodemographically diverse groups and to those with chronic health conditions. Substantial evidence supports the validity of the PROMIS-29. ${ }^{69} 70$ In addition, the seven-item Center for Epidemiologic Studies Depression Scale (CES-D) is used to assess how often a participant felt depressive symptoms 
during the past week (1=never, $2=$ hardly ever, $3=$ some of the time, $4=$ most of the time). The CES-D has shown adequate reliability and validity in general population samples with a range of demographic characteristics. ${ }^{71-74}$

Incentive programme preferences: using an item adapted from the Financial Incentives for Smoking Treatment study (ClinicalTrials.gov identifier NCT02506829), the RA describes two hypothetical financial incentive programmes for weight loss (one is goal directed and the other is outcome based), and then asks which programme the participant prefers. This question allows us to test whether participants who are randomised to an incentive structure consistent with their prespecified incentive programme preference are more likely to lose weight than those who are randomised to incentives that are inconsistent with their preference. To understand the participant's programme choice, the RA asks openended questions to assess the reasons why the participant chose the programme they did and what concerns about the programme they have, as well as open-ended items adapted from the Health Incentive Program Questionnaire $^{75}$ to prompt the participant to describe their reactions to receiving payment for losing weight.

Food behaviour: we assess healthy dietary changes in portion sizes and food choices such as fried food, fast food and white bread using the Latino Dietary Behaviors Questionnaire (LDBQ). This subscale reflects a pattern of dietary behaviours associated with healthier micronutrients and lower calories. ${ }^{76}$ Fruit and vegetable consumption is measured using a seven-item subscale from the validated Food Behavior Checklist. ${ }^{77}$ We adapted two items from the Rapid Eating Assessment for Participants - Shortened Version to assess consumption of sweets and salty snacks. ${ }^{7879}$ The LDBQ is also used to assess consumption of and sugar-sweetened beverages. ${ }^{76}$ Binge eating, characterised by a high frequency of consuming unusually large amounts of food and feeling a loss of control, is assessed using the Eating Disorder Diagnostic Scale ${ }^{80}$ For pragmatic reasons, we did not use longer food behaviour questionnaires or 24-hour dietary recalls due to their time-intensiveness.

Physical activity: walking and moderate-to-vigorous intensity physical activity (MVPA) are measured using the International Physical Activity Questionnaire short form (IPAQ-SF). The IPAQ is well established in the public health literature as a valid and reliable physical activity assessment tool. ${ }^{81} 82$ For the duration of the study, participants wear a commercially available fitness tracker (Fitbit Alta HR), which has pedometer and accelerometer functions. The validity of similar activity tracker models for assessing MVPA has been established against an accelerometer criterion, with results ranging from near perfect correlation to overestimation of MVPA values. ${ }^{83}$ Fitbit algorithms take into account the Alta HR's accelerometer movement and heart rate function, applying minute-byminute metabolic equivalents to estimate activity intensity. In 2015, Fitbit improved their algorithm to more closely align with 2008 physical activity guidelines for adults ${ }^{63}$ so that moderate-to-vigorous intensity activity minutes must occur in bouts of at least $10 \mathrm{~min}$ for a minute to be classified as an 'active minute'. Therefore, $\geq 150$ Fitbit 'active minutes' per week are considered an approximation of the recommended $\geq 150 \mathrm{~min}$ of MVPA per week.

RAs instruct participants to wear their Fitbit device at all times, except during bathing and swimming. RAs demonstrate how to charge the device and sync it with a smartphone, thereby allowing physical activity data to be uploaded to Fitabase. Fitabase is an independent affiliate of Fitbit that allows researchers to centrally access data from Fitbit wearable devices. A participant is considered to have worn their device on any given day if they accumulate $>500$ steps. Participants considered adherent accumulate $\geq 150$ active minutes per week in the 28 days prior to their study visits. For participants who do not have a smartphone or computer, the RA syncs the Fitbit during study visits, allowing data stored on the device in the previous 30 days to be uploaded.

Adherence to weight management programme participation and self-monitoring weight and diet: to assess past-month participation in a recommended weight management programme, participants who report attending a programme in the previous month are asked how many sessions $(1-5+)$ they attended and to provide approved documentation of attendance at each session. Based on thresholds established in previous studies, ${ }^{20} 58$ participants considered adherent attend a session on-site at least twice in the previous month, or at least $50 \%$ of sessions offered by the programme (whichever is greater), and provide documentation during their study visit. To measure past-month adherence to self-monitoring strategies, participants who report recording their weight and diet in the previous month are asked how many days in a typical week $(1-5+)$ they did so, and then to provide weight and food records. Similar to thresholds identified in previous studies ${ }^{84-86}$ participants considered adherent weigh themselves $\geq 3$ days per week in the previous month and record what and how much they eat $\geq 5$ days per week and provide records during their study visit.

Theoretical indicators of health behaviour change: several theoretical constructs inform the design of this intervention. We use established instruments to assess changes in the following: (1) self-efficacy to resist overeating (Weight Efficacy Lifestyle Questionnaire short form $^{87}$ ) and engage in regular physical activity, ${ }^{88}$ (2) outcome expectations for weight loss and physical activity $^{89}$ and (3) intrinsic motivation for weight loss programme participation, self-monitoring (Treatment Self-Regulation Questionnaire ${ }^{90}$ ) and physical activity (Behavioral Regulation in Exercise Questionnaire ${ }^{91}$ ). These constructs will be considered as potential mediators of the effects of the intervention on health behaviour change.

Medical history and healthcare utilisation: we use the EHR, administrative databases, baseline chart abstraction and survey items adapted from the NHANES Medical Conditions Survey and Cardiovascular Disease 
Questionnaire $^{92}$ to obtain: (1) discharge diagnoses and comorbidities, (2) length of stay, (3) medications prescribed, (4) out-of-pocket expenditures for healthcare services and (5) number of outpatient visits, emergency department visits, and hospitalisations that occur in the 6 months prior to enrolment and within 1 year after enrolment.

Financial well-being: the extent to which a participant's financial status contributes to their sense of financial security and well-being is captured using the five-item Consumer Financial Protection Bureau Financial Wellbeing Scale. ${ }^{93}$ Because adults with lower incomes may be more responsive to financial incentives, ${ }^{22}$ higher levels of financial distress may also identify participants with a greater likelihood of weight loss in response to financial incentives. ${ }^{94}$ We measure financial well-being at baseline and follow-up to assess for this potential effect, because its presence would have implications for the development of incentive interventions that address socioeconomic disparities. ${ }^{95}$

Alcohol and tobacco use: the Alcohol Use Disorders Identification Test Consumption, an effective screening tool among primary care patients, is administered at screening and 12 months to assess the extent to which a participant is at risk for alcohol misuse based on Diagnostic and Statistical Manual of Mental Disorders (DSM-5) criteria (ie, score >8). ${ }^{96}$ The participant's history and current frequency and duration of cigarette and e-cigarette smoking are assessed using items adapted from the California Tobacco Survey. ${ }^{97}$

Resource utilisation measures: we measure RA time spent obtaining biometric measurements, providing education and resources, confirming programme participation, food journal use and physical activity minutes, and administering incentives. While research-related costs are not included in our economic analysis, the cost of performing activities like measurements would be incurred if the programme is disseminated, since these types of activities must be performed to confirm eligibility for financial incentives.

Demographic characteristics/covariates: covariates include but are not limited to age, gender, race/ethnicity, education level, acculturation, marital status, employment status, household composition, use of technology, walking limitations and chronic conditions/disease.

\section{Statistical analysis}

Descriptive analysis: we will use descriptive statistics (mean, SD, median, IQR and frequency distribution) to summarise baseline demographic, socioeconomic and clinical information to characterise the study population. We will summarise all outcomes of interest by study visits and by study arms. Graphic displays, such as boxplots and histograms, will be used to inspect the variable distributions and identify possible outliers.

Analysis of weight loss outcomes: to examine the effectiveness of the intervention on $\geq 5 \%$ wt loss, we will use generalised mixed-effect models for repeated measures as the main inferential analytic framework. In addition to treatment, time and treatment-time interaction, the models will include randomisation stratification variables of study site and participant's incentive preference as fixed effects. The participant will be included as the random effect to account for within-subject correlation. Appropriate contrast will be used to provide estimates and comparisons of outcomes between intervention groups. We will consider variable transformation, such as log-transformation, if the distribution is skewed and normality distribution assumption is imperative. All analysis will follow the intention-to-treat principle, all tests will be two sided and Bonferroni correction will be applied for multiple comparisons among study arms. We will analyse goal-directed indicators (weight management programme attendance, self-monitoring, physical activity and healthy eating) and secondary outcomes (mean weight change, waist circumference, blood pressure and quality of life) similarly to our primary outcome.

We will handle missing data, whether due to missed visits or early dropout and loss to follow-up, by the mixed effects models in the main analysis, which assume that the missing data mechanisms are 'missing at random'. Pattern mixture models, which allow missing not-at-random data, will be carried out as a missing data sensitivity analysis. In particular, we will impute the missing data according to the worst-case scenario that there is no intervention effect and all missing data follow the distribution of observed data in the control arm.

Cost-effectiveness: we will estimate the cost of the intervention to help guide employers and policymakers considering adopting the programme and to provide inputs for our cost-effectiveness analysis, while adhering to recommendations of the Panel on Cost-Effectiveness in Health and Medicine. ${ }^{98}$ We will estimate the return on investment of our financial incentives intervention from the perspective of the healthcare system (hospitalisations, ambulatory care and medications) on a per-patient basis, assuming that a healthcare system would administer the programme. We include a return on investment analysis because prior research has shown that providing return on investment may influence the adoption and sustainability of health improvement programmes by healthcare organisations. ${ }^{47}$ Using a timeline of $5-10$ years, ${ }^{47}$ we will determine costs by: (1) multiplying staff or employee wages (based on US Bureau of Labor Statistics values ${ }^{99}$ ) by the projected time they spend on programme administration, such as obesity weigh-ins and confirmation of weight loss programme participation $^{100}$; (2) using the Red Book to estimate medication costs for hypertension, diabetes and other conditions, based on average wholesale prices ${ }^{101}$; and (3) estimating bulk purchase prices for other physical materials given to patients with obesity. We have applied these methods to prior economic evaluations. ${ }^{38}$ 102-108 Prior research suggests that private health plans and corporations use a shorter return on investment time horizon (eg, 5-10 years) for decision making; however, it is important to 
note that some health improvement programmes may require longer time horizons for economic benefits to accrue.

Resources consumed in programme activities include personnel time, printed materials, postage, telephone use and other miscellaneous items. We will estimate personnel time using tracking sheets and/or reports made by study staff and carefully document other materials used to deliver the intervention. These logs will include information about how the resources contributed to delivering our intervention, so that we can distinguish fixed costs (costs that do not change with the number of participants in the programme) from variable costs (costs that increase with the number of participants in the programme), an important distinction in economic evaluation. ${ }^{109}$ Costs associated with research assessments (eg, screening, randomisation and questionnaires) will not be included.

We will estimate return on investment using the difference between the value of financial incentives provided and incremental healthcare costs or savings, comparing the outcome-based financial incentives arm to the resources-only arm, and the goal-directed arm to the outcome-based arm. To project long-term return on investment (using a lifetime horizon), we will modify an existing Markov model that we previously developed of treatment interventions for patients with hypertension (cardiometabolic risks incorporated in this model reflect risks faced by obese patients). This model currently uses a 10-year time horizon.

We will also estimate the cost-effectiveness of the intervention (cost per pound of weight loss and cost per lifeyear gained) using the ratio of the difference in costs between each of the intervention and control arms to the difference in $5 \%$ wt loss attainment rates between each of the intervention and control arms. The general equation for a cost-effectiveness ratio (CER) is ${ }^{110}$ shown in figure 3 , where $i$ is the $i$-th time period of a patient's life, cost is determined by resources used in the provision of weight loss resources and support in the intervention and control arms and effectiveness is measured by the primary outcome and quality of life (PROMIS-29). Costs will be determined as described above. In addition, to estimate potential cost-offsets, we will use data from our survey's sociodemographic questions about employment to evaluate changes in productivity. We will also perform non-parametric bootstrapping with 1000 random samples from our study arms to estimate CIs for CERs, using the bias-corrected percentile method described by Efron and others. ${ }^{111-115}$ The cost and effectiveness outcomes from each bootstrap sample will be plotted on a cost-effectiveness plane.

$$
C E R=\frac{\sum_{i}\left(\text { Cost }_{\text {intervention }, i}-\text { Cost }_{\text {usual care }, i}\right)}{\sum_{i}\left(\text { Effectiveness }_{\text {intervention }, i}-\text { Effectiveness }_{\text {usual care }, i}\right)}
$$

Figure 3 General equation for cost-effectiveness ratio.

\section{Patient and public involvement}

We sought feedback from patients enrolled in a prior incentives study on their preferences for an incentive structure (ie, goal-directed vs outcome-based incentives for a preventive health behaviour) and used this feedback to inform FIReWoRk's framework and intervention design. Patients were not involved in the recruitment and conduct of the study. We assess the burden of the intervention among FIReWoRk participants during an exit interview. We will make a summary of the results available to the public after the study's conclusion and publication of the primary outcomes.

\section{DISCUSSION}

\section{Innovation}

In this paper, we outline the protocol and rationale for the FIReWoRk study. FIReWoRk is innovative for several reasons. First, financial incentive interventions for preventive health have primarily targeted outcomes. ${ }^{42}$ A few recent weight loss trials have demonstrated effectiveness using a combination of goal-directed and outcome-based incentives versus a non-incentive comparison. $^{36116117}$ The few trials comparing goal-directed versus outcome-based financial incentives for weight loss were underpowered ${ }^{118}$ or preceded behavioural economics. ${ }^{119-122}$ Testing goal-directed versus outcomebased incentives is important because it directly addresses outstanding questions about how to structure incentive interventions optimally, while also yielding insights into the value of incentive-based versus non-incentive-based strategies for behaviour change. A recent cluster-randomised trial ${ }^{123}$ compared the effectiveness of earning up to US\$310 over 16 weeks for attending Diabetes Prevention Program sessions versus for losing weight versus a combination of the two incentive types. All groups achieved moderate weight loss at 16 weeks, though no differences in weight loss were observed between the three intervention arms. Participants in the goal-directed arm were more likely to meet their programme attendance goal than either the outcomebased or combined incentive arms. FIReWoRk expands on this recent study by providing monthly primary care clinic-based check-in visits, incentivising multiple behavioural goals, administering larger and more immediate payments ( $<48$ hours vs $<2$ months) and assessing short-term weight maintenance at 3 months and 6 months postintervention. We hypothesise that goal-directed incentives will lead to greater and more sustained weight loss than outcome-based incentives or the provision of behaviour change resources alone. If confirmed, this finding would reinforce the importance of longstanding behavioural approaches to treating obesity and other chronic health conditions with effective, goal-directed strategies (eg, self-monitoring for weight loss, use of counselling and nicotine replacement therapy for smoking cessation). However, if FIReWoRk demonstrates that outcome-based incentives are more effective 
than goal-directed incentives or resources alone, this finding would support the need to: (1) explore the role of outcome-based incentives in maintaining weight loss and (2) make more rigorous comparisons between economically sustainable outcome-based incentive strategies and conventional, non-incentive-based approaches to treating obesity and chronic health conditions.

Measuring participants' weight at 12 months after enrolment -6 months after removal of incentives-will provide preliminary insight into the durability of financial incentives for weight loss. Understanding the durability of financial incentives is directly relevant to ongoing debates about the effect of incentives on intrinsic versus extrinsic motivation and patient decision making about preventive health. Researchers have raised concerns that financial incentives may crowd out intrinsic motivation, ${ }^{124125}$ though some have noted that levels of intrinsic motivation for activities we incentive may already be low, leaving little motivation at risk for crowd out. ${ }^{126}$ The possibility that losing weight may itself increase self-efficacy and intrinsic motivation ${ }^{127}$ further complicates the intrinsic-extrinsic motivation dynamic in the context of weight loss.

FIReWoRk is also innovative because it leverages existing clinic and community resources. The USPSTF recommends that all patients with obesity receive an intensive multicomponent behavioural lifestyle intervention, ${ }^{11}$ but most healthcare centres lack weight management programmes. Even when health systems have their own programmes (eg, the Veteran's Affairs MOVE! Program), patients often do not live close enough to attend regularly. Thus, we collaborate with WW International, Inc because WW Freestyle is a ubiquitous resource in the community with multiple studio locations.

A third innovative quality of FIReWoRk is its use of Fitbit wearable devices and Fitabase to facilitate the provision of financial incentives. Fitbit technology provides an interface we use to verify all participants' physical activity goal attainment, allowing us to provide timely incentive payments to participants in the goal-directed arm. These data, which include step counts, heart rate, activity intensity, energy expenditure and sleep, will also allow us to richly evaluate how different biometric measures influence obesity and weight loss outcomes. We chose not to target wearable tracking of physical activity with goal-directed incentives given that such self-monitoring of physical activity alone may not be effective for weight loss. ${ }^{128}$ Instead, participants must meet public health guidelines for moderate-to-vigorous physical activity to receive incentives. We considered adopting other technological innovations to enhance our ability to administer incentives immediately, including scales that wirelessly transmit weight data. However, our concern with using some of these technologies in an incentive intervention is that remote monitoring that cannot readily be verified may tempt some participants to misrepresent their weight or other information. However, even these obstacles can be attenuated or overcome with technology. For example, video monitoring could be embedded into remote weigh-ins.

A fourth innovative component of FIReWoRk is its explicit focus on the effects of incentives on financial well-being. To increase our ability to detect such an effect, we are enrolling low-income populations. Low-income patients may be more likely to respond to incentives, ${ }^{22} 129$ and their socioeconomic status suggests that the marginal benefit of gains in health and income may be greater than those experienced by similarly obese patients with greater economic resources. Any potential benefits to financial well-being would therefore have implications for the development of incentive interventions that address socioeconomic disparities. Because of its design, FIReWoRk may also contribute to the growing literature on the effects of incentives to induce personal investments in health and social capital through activities such as acquiring vaccinations, saving money or enrolling in school. ${ }^{95}$ Several published trials of income support sample low-income populations, and some have yielded promising results with benefits extending into health and social domains. ${ }^{95} 130$

Finally, FIReWoRk leverages important constructs from behavioural sciences, but these constructs represent only a fraction of those embedded into prior trials. Effective interventions have applied such constructs ${ }^{131}{ }^{132}$; however, it is worth noting that incorporating these theories does not ensure that an intervention will be successful. ${ }^{133} \mathrm{We}$ are exploring the application of broader behavioural concepts in future work. In particular, we are interested in leveraging the power of social norms, peer comparisons and self-image to increase weight loss. ${ }^{134}$

\section{Limitations}

A major challenge of our intervention design is that simultaneous use of multiple weight loss techniques limits our ability to determine which components of the intervention most effectively promote weight loss. However, using ad hoc analyses, we will be able to identify which components are associated with the highest rates of response to incentive payments. All participants receive substantial resources, including a 1-year commercial weight loss programme membership (mean 6-month weight loss $4.6 \mathrm{~kg}$ ), ${ }^{20}$ which may reduce marginal sensitivity to the effects of incentives over resources alone. However, regular programme attendance, which is necessary for weight loss success, ${ }^{20}$ is often low, and goal-directed financial incentives have been shown to increase weight loss programme participation in real-world settings. ${ }^{123}$ Adherence to monthly check-in visits is also of concern, so participants are compensated $\$ 20$ to promote retention and offset transportation costs to study visits. These smaller payments may also reduce our ability to detect the marginal impact of the incentives through their income effect, though this effect is likely negligible. The comparative effectiveness of goal-directed versus outcome-based incentives may favour goal-directed incentives if the total incentive value were more modest than $\$ 750$. This 
possibility is an appropriate subject for future investigation, assuming that incentives that are more modest remain sufficiently large to promote weight loss. By setting the reward amount equally across both incentive arms, cost-effectiveness may favour outcome-based incentives, particularly if weight loss is similar between arms. In the goal-directed arm, participants may inflate their goal attainment in order to increase their incentive amount, though we expect our objective goal verification process to mitigate most of this risk. Several of our measures are self-report, which can introduce social desirability bias in patients' responses. RAs are not blinded to participants' intervention group when administering weight and survey measures at 6,9 and 12 months, which could result in measurements that inadvertently favour the RAs preferred participants or incentive strategy.

Our recruitment strategies may entice patients who are more highly motivated to lose weight than a truly representative sample of primary care patients, thus overestimating intervention effects on weight loss. We also screen patients for eligibility based on neighbourhood-level rather than individual or household income, which precludes enrolment of low-income patients living in higher income areas and may affect the generalisability of our sample.

\section{Public health and policy considerations}

We view FIReWoRk's major limitation in the context of public policy to be uncertainty about the sustainability and acceptability of financial incentives for weight loss in individuals with obesity. The use of financial incentives to improve health can be controversial. ${ }^{23}$ Sustainability and acceptability largely relate to: (1) economic sustainability, in terms of identifying sources of funding, and (2) ethics, that is, public perceptions of the fairness and appropriateness of financial incentives. ${ }^{131}{ }^{135-137}$ Despite these concerns, some decision makers have already adopted effective financial incentive programmes. ${ }^{138}$ For example, the NHS Tayside programme in Scotland provided pregnant smokers with support and $£ 50$ per month in shopping vouchers for negative carbon monoxide breath tests. ${ }^{139}$ Australia addressed low rates of childhood vaccination by linking eligibility for social security payments, childcare rebates and other payments to immunisation status. ${ }^{140}{ }^{141}$ In 2015, CVS Health launched a financial incentive programme to help employees quit smoking, based on the design of a successful randomised trial. ${ }^{142} 143$ A number of health insurance companies and other workplaces have also adopted incentive programmes to improve health. Nonetheless, acceptability is an important consideration when designing and implementing financial incentive programmes for weight loss, and even effective programmes have encountered resistance. ${ }^{144}$

Our view is that challenges related to sustainability and acceptability are surmountable and that we can design incentive programmes in a manner that supports public perceptions of fairness. ${ }^{145} 146$ For example, one approach is to broaden the number of individuals eligible for incentives, while tailoring behavioural targets and incentive amounts to ensure that individuals with greatest need benefit most. ${ }^{147148}$ In terms of funding for incentives, early investment in selective programmes may be offset by reductions in future healthcare cost. Some political philosophies may also be receptive to shifting investments from public programmes to more targeted programmes that directly benefit individuals. FIReWoRk does not address population-based approaches to weight loss, such as reducing sugar-sweetened beverage sales or increasing opportunities for physical activity in the built environment-which may ultimately be most cost-effective-but rather focuses on individual decision making.

\section{Summary and significance}

FIReWoRk responds to gaps in existing evidence by examining the comparative effectiveness and cost-effectiveness of goal-directed versus outcome-based financial incentives for weight loss in socioeconomically disadvantaged patients with obesity. We anticipate that the results of this study will inform the design of scalable financial incentive programmes to address obesity in public and private health systems.

\section{Trial status}

FIReWoRk began enrolment in November 2017. We expect to complete enrolment in June 2020 and complete the outcome assessment between June and August 2021. Enrolment and study execution have required close collaboration between investigators, research staff and partners at our multiple clinical sites.

\section{Author affiliations}

${ }^{1}$ Departments of Medicine and Population Health, New York University School of Medicine, New York, New York, USA

${ }^{2}$ Division of General Internal Medicine and Clinical Innovation, Department of Medicine, New York University School of Medicine, New York, New York, USA ${ }^{3}$ Department of Medicine, Olive View-University of California Los Angeles (UCLA) Medical Center, Sylmar, California, USA

${ }^{4}$ Division of Health Promotion and Nutrition Research, Department of Epidemiology and Population Health, Albert Einstein College of Medicine, Bronx, New York, USA ${ }^{5}$ Division of General Internal Medicine and Health Services Research, Department of Medicine, David Geffen School of Medicine at UCLA, Los Angeles, California, USA

${ }^{6}$ Anderson School of Management at UCLA, University of California Los Angeles, Los Angeles, California, USA

Acknowledgements We would like to thank our research staff for their many contributions to the project: Miguel Cuevas, Christina Hernandez, Wendy Arriaga, Norma Guerra, Susan Parraga, Cassie DeWitt and Robert Brandon Ponce. We would also like to extend our gratitude to our volunteer research assistants who keep the study running: Azucena Fuentes, Tom Harlington Hanna, Ololade Afolayan, Tiffany Martinez, Eduardo Corona and Riana Liang Chen. We also thank Dr Olga Filipova, Ms AnneMarie Sabella, Ms Zerena Khan, Ms Theresa Basso, Dr Andrew Wallach, Dr Isaac Holms and Dr Jessica Tanenbaum for their partnership and WW International, Inc for providing memberships to our participants. Not least of all, we thank all of the patients who participated in the study.

Contributors JAL and MJ initiated collaboration, conceived of and obtained funding for the project. JW-R, SBS and NJG helped with study design. JAL, MJ, SLO, C-HT, SW, JW-R, SBS and NJG developed the survey and data collection tools. $\mathrm{C}-\mathrm{HT}$ and JAL devised the statistical analysis plan, and SLO and C-HT monitor data collection. MJ and SLO developed the conceptual model. SLO developed intervention materials and protocols. SLO is managing the project day to day and supervising staff. MJ, SLO, and VS administer the trial in New York City, and SW 
administers the trial in LA County. SLO, JAL and MJ drafted and revised the paper. All coauthors contributed to the conception and/or design of the work and critically reviewed and approved the final manuscript.

Funding This research is supported by the US Department of Health and Human Services National Institute of Minority Health and Health Disparities grant number R01MD011544. This research is supported in part by the NYU CTSA grant number UL1TR001445 from the National Center for Advancing Translational Sciences, NIH.

Competing interests None declared.

Patient consent for publication Not required.

Provenance and peer review Not commissioned; externally peer reviewed.

Open access This is an open access article distributed in accordance with the Creative Commons Attribution Non Commercial (CC BY-NC 4.0) license, which permits others to distribute, remix, adapt, build upon this work non-commercially, and license their derivative works on different terms, provided the original work is properly cited, appropriate credit is given, any changes made indicated, and the use is non-commercial. See: http://creativecommons.org/licenses/by-nc/4.0/.

\section{REFERENCES}

1. Nguyen NT, Magno CP, Lane KT, et al. Association of hypertension, diabetes, dyslipidemia, and metabolic syndrome with obesity: findings from the National Health and Nutrition Examination Survey, 1999 to 2004. J Am Coll Surg 2008;207:928-34.

2. Haslam DW, James WPT. Obesity. The Lancet 2005;366:1197-209.

3. Hales CM CM, Fryar CD, Ogden CL. Prevalence of obesity among adults and youth: United States, 2015-2016. In: NCHS data brief. Hyattsville, MD: National Center for Health Statistics, 2017;288.

4. Statistics Team ND. Statistics on Obesity, Physical Activity and Diet - England, 2018. Richmond, United Kingdom: Government Statistical Service, 2018.

5. Obesity and the Economics of Prevention: Fit not Fat - United Kingdom (England) Key Facts. http://www.oecd.org/els/healthsystems/obesityandtheeconomicsofpreventionfitnotfat-unitedki ngdomenglandkeyfacts.htm

6. Drewnowski A, Rehm CD, Solet D. Disparities in obesity rates: analysis by ZIP code area. Soc Sci Med 2007;65:2458-63.

7. Puhl RM, Heuer CA. Obesity stigma: important considerations for public health. Am J Public Health 2010;100:1019-28.

8. Finkelstein EA, Trogdon JG, Cohen JW, et al. Annual medical spending attributable to obesity: payer-and service-specific estimates. Health Aff 2009;28:w822-w831.

9 Health matters: obesity and the food environment. https://www.gov. uk/government/publications/health-matters-obesity-and-the-foodenvironment/health-matters-obesity-and-the-food-environment-2

10. Moyer VA. U.S. Preventive Services Task Force. Screening for and management of obesity in adults: U.S. Preventive Services Task Force recommendation statement. Ann Intern Med 2012;157:373-8.

11. USPSTF: Draft Recommendation Statement. Weight Loss to Prevent Obesity-Related Morbidity and Mortality in Adults: Behavioral Interventions. In: Force USPST, 2018.

12. Bleich SN, Pickett-Blakely O, Cooper LA. Physician practice patterns of obesity diagnosis and weight-related counseling. Patient Educ Couns 2011;82:123-9.

13. Gallup's Health and Healthcare survey: Americans' Effort to Lose Weight Still Trails Desire. http://www.gallup.com/poll/179771/ americans-effort-lose-weight-trails-desire.aspx

14. Kahwati LC, Lance TX, Jones KR, et al. RE-AIM evaluation of the Veterans Health Administration's MOVE! Weight Management Program. Trans/ Behav Med 2011;1:551-60.

15. Powell TM, et al. Body size misperception: a novel determinant in the obesity epidemic. Arch Intern Med 2010;170:1695-7.

16. Wing RR, Lang W, Wadden TA, et al. Benefits of Modest Weight Loss in Improving Cardiovascular Risk Factors in Overweight and Obese Individuals With Type 2 Diabetes. Diabetes Care 2011;34:1481-6.

17. Aucott L, Poobalan A, Smith WCS, et al. Effects of Weight Loss in Overweight/Obese Individuals and Long-Term Hypertension Outcomes. Hypertension 2005;45:1035-41.

18. Knell G, Li Q, Pettee Gabriel K, et al. Long-Term Weight Loss and Metabolic Health in Adults Concerned With Maintaining or Losing Weight: Findings From NHANES. Mayo Clin Proc 2018;93:1611-6.

19. Knowler WC, Barrett-Connor E, Fowler SE, et al. Diabetes Prevention Program Research Group. Reduction in the incidence of type 2 diabetes with lifestyle intervention or metformin. $N$ Engl J Med 2002;346:393-403.
20. Johnston CA, Rost S, Miller-Kovach $\mathrm{K}$, et al. A randomized controlled trial of a community-based behavioral counseling program. Am J Med 2013;126:1143.e19-24.

21. Dahn JR, Fitzpatrick SL, Llabre MM, et al. Weight management for veterans: examining change in weight before and after MOVE! Obesity (Silver Spring, Md), 2011;19:977-81.

22. Haff N, Patel MS, Lim R, et al. The role of behavioral economic incentive design and demographic characteristics in financial incentive-based approaches to changing health behaviors: a metaanalysis. Am J Health Promot 2015;29:314-23.

23. Strickland $\mathrm{S}$. Does it work to pay people to live healthier lives? BMJ 2014;348:g2458

24. Full Report: Towers Watson/NBGH 2013/2014 Employer Survey on Purchasing Value in Health Care. http://www.towerswatson.com/enUS/Insights/IC-Types/Survey-Research-Results/2014/05/full-reporttowers-watson-nbgh-2013-2014-employer-survey-on-purchasingvalue-in-health-care

25. Loewenstein G, Prelec D. Anomalies in Intertemporal Choice: Evidence and an Interpretation. Q J Econ 1992;107:573-97.

26. Mehrotra A, Sorbero ME, Damberg CL. Using the lessons of behavioral economics to design more effective pay-for-performance programs. Am J Manag Care 2010;16:497-503.

27. Connolly T, Butler D. Regret in economic and psychological theories of choice. J Behav Decis Mak 2006:19:139-54.

28. Colin C, Teck HH. Experience-weighted Attraction Learning in Normal Form Games. Econometrica 1999;67:827-74.

29. Moller AC, McFadden HG, Hedeker D, et al. Financial Motivation Undermines Maintenance in an Intensive Diet and Activity Intervention. J Obes 2012;2012:1-8.

30. Jeffery RW, Bjornson-Benson WM, Rosenthal BS, et al. Behavioral treatment of obesity with monetary contracting: Two-year follow-up. Addict Behav 1984;9:311-3.

31. Jolly K, Lewis A, Beach J, et al. Comparison of range of commercial or primary care led weight reduction programmes with minimal intervention control for weight loss in obesity: Lighten Up randomised controlled trial. BMJ 2011;343:d6500.

32. Kullgren JT, Troxel AB, Loewenstein G, et al. Individual- versus group-based financial incentives for weight loss: a randomized, controlled trial. Ann Intern Med 2013;158:505-14.

33. Finkelstein EA, Linnan LA, Tate DF, et al. A Pilot Study Testing the Effect of Different Levels of Financial Incentives on Weight Loss Among Overweight Employees. J Occup Environ Med 2007;49:981-9.

34. Garcia DO, Jakicic JM, Davis KK, et al. A Pilot Feasibility Study of a Campaign Intervention for Weight Loss among Overweight and Obese Adults. 2014.

35. Leahey T, Rosen J. DietBet: a web-based program that uses social gaming and financial incentives to Promote weight loss. JMIR Serious Games 2014;2:e2.

36. Leahey TM, Subak LL, Fava J, et al. Benefits of adding small financial incentives or optional group meetings to a web-based statewide obesity initiative. Obesity 2015;23:70-6.

37. Spring B, Schneider K, McFadden HG, et al. Multiple behavior changes in diet and activity: a randomized controlled trial using mobile technology. Arch Intern Med 2012;172:789-96.

38. Ladapo JA. Paying Smokers to Quit: Does It Work? Should We Do It? J Am Coll Cardiol 2016;68:786-8.

39. Bodenheimer T, Handley MA. Goal-setting for behavior change in primary care: An exploration and status report. Patient Educ Couns 2009;76:174-80.

40. Bandura A. Social foundations of thought and action: A social cognitive theory. Upper Saddle River, NJ: Prentice-Hall, 1986.

41. Ryan RM, Deci EL. Self-determination theory: Basic psychological needs in motivation, development, and wellness. 2017.

42. Paul-Ebhohimhen V, Avenell A. Systematic review of the use of financial incentives in treatments for obesity and overweight. Obesity Reviews 2008;9:355-67.

43. Mantzari E, Vogt F, Shemilt I, et al. Personal financial incentives for changing habitual health-related behaviors: A systematic review and meta-analysis. Prev Med 2015;75:75-85.

44. Jeffery RW. Financial incentives and weight control. Prev Med 2012;55:S61-S67.

45. John LK, Loewenstein G, Troxel AB, et al. Financial Incentives for Extended Weight Loss: A Randomized, Controlled Trial. J Gen Intern Med 2011;26:621-6.

46. Mitchell MS, Goodman JM, Alter DA, et al. Financial incentives for exercise adherence in adults: systematic review and meta-analysis. Am J Prev Med 2013;45:658-67.

47. Leatherman S, Berwick D, lles D, et al. The Business Case For Quality: Case Studies And An Analysis. Health Aff 2003;22:17-30. 
48. Franz MJ, VanWormer JJ, Crain AL, et al. Weight-Loss Outcomes: A Systematic Review and Meta-Analysis of Weight-Loss Clinical Trials with a Minimum 1-Year Follow-Up. J Am Diet Assoc 2007; 107:1755-67.

49. U.S. Bureau of the Census. In Edited by American Community Survey ACS-YE, Table B19013; generated using American FactFinder, 2015. http://factfinder.census.gov.

50. Flores $\mathrm{G}$, Portillo A, Lin H, et al. A successful approach to minimizing attrition in racial/ethnic minority, low-income populations. Contemp Clin Trials Commun 2017;5:168-74.

51. Warner ET, Glasgow RE, Emmons KM, et al. Recruitment and retention of participants in a pragmatic randomized intervention trial at three community health clinics: Results and lessons learned. BMC Public Health 2013;13:192.

52. Damschroder LJ, Lutes LD, Kirsh S, et al. Small-changes obesity treatment among veterans: 12-month outcomes. Am J Prev Med 2014;47:541-53

53. Patel MS, Asch DA, Troxel AB, et al. Premium-Based Financial Incentives Did Not Promote Workplace Weight Loss In A 2013-15 Study. Health Aff 2016;35:71-9.

54. Appel LJ, Clark JM, Yeh H-C, et al. Comparative Effectiveness of Weight-Loss Interventions in Clinical Practice. N Engl J Med Overseas Ed 2011;365:1959-68.

55. Wadden TA, Volger S, Tsai AG, et al. Managing obesity in primary care practice: an overview with perspective from the POWER-UP study. Int J Obes 2013;37(S1):S3-11.

56. Slater BA, Huang Y, Dalawari P. The Impact of Teach-Back Method on Retention of Key Domains of Emergency Department Discharge Instructions. J Emerg Med 2017;53:e59-e65.

57. Lentz J, Kennett M, Perlmutter J, et al. Paving the way to a more effective informed consent process: Recommendations from the Clinical Trials Transformation Initiative. Contemp Clin Trials 2016;49:65-9.

58. Jensen MD, Ryan DH, Apovian CM, et al. AHA/ACC/TOS guideline for the management of overweight and obesity in adults: A report of the American College of cardiology/American Heart Association task force on practice guidelines and the obesity society. Circulation 2014;2013.

59. Dombrowski SU, Sniehotta FF, Avenell A, et al. Identifying active ingredients in complex behavioural interventions for obese adults with additional risk factors: A systematic review. Health Psychol Rev 2012;6:7-32.

60. Michie S, Abraham C, Whittington C, et al. Effective techniques in healthy eating and physical activity interventions: A metaregression. Health Psychol 2009;28:690-701.

61. Burke LE, Wang J, Sevick MA. Self-Monitoring in Weight Loss: A Systematic Review of the Literature. J Am Diet Assoc 2011;111:92-102.

62. de Vries HJ, Kooiman TJM, van Ittersum MW, et al. Do activity monitors increase physical activity in adults with overweight or obesity? A systematic review and meta-analysis. Obesity 2016;24:2078-91.

63. Buchner D, Bishop J, Brown D, et al. Physical Activity Guidelines for Americans. Washington DC: U.S. Department of Health and Human Services, Centers for Disease Control and Prevention, National Center for Chronic Disease Prevention and Health Promotion 2008.

64. Sharif MA, Shu SB. The Benefits of Emergency Reserves: Greater Preference and Persistence for Goals that Have Slack with a Cost. J Mark Res 2017;54:495-509.

65. Borrelli B. The assessment, monitoring, and enhancement of treatment fidelity in public health clinical trials. J Public Health Dent 2011;71:S52-S63.

66. Malone M, Alger-Mayer SA. Medication associated with weight gain may influence outcome in a weight management program. Ann Pharmacother 2005;39:2046-55.

67. Disease C. Centers for Prevention. Behavioral Risk Factor Surveillance System Questionnaire Atlanta, 2012

68. Friedberg JP, Rodriguez MA, Watsula ME, et al. Effectiveness of a tailored behavioral intervention to improve hypertension control: primary outcomes of a randomized controlled trial. Hypertension 2015;65:440-6.

69. Ader DN. Developing the Patient-Reported Outcomes Measurement Information System (PROMIS). Med Care 2007;45:S1-S2.

70. Riley WT, Rothrock N, Bruce B, et al. Patient-reported outcomes measurement information system (PROMIS) domain names and definitions revisions: further evaluation of content validity in IRTderived item banks. Quality of Life Research 2010;19:1311-21.

71. Carleton RN, Thibodeau MA, Teale MJ, et al. The center for epidemiologic studies depression scale: a review with a theoretical and empirical examination of item content and factor structure. PLoS One 2013:8:1.
72. Radloff LS. The CES-D scale: a self-report depression scale for research in the general population. Appl Psychol Meas 1977;1:385-401.

73. Salinas-Rodriguez A, Manrique-Espinoza B, Acosta-Castillo I, et al. Validation of a cutoff for the Depression Scale of the Center for Epidemiologic Studies, Brief Version (CESD-7). Salud publica de Mexico 2013;55:267-74

74. Levine SZ. Evaluating the seven-item Center for Epidemiologic Studies Depression Scale short-form: a longitudinal US community study. Soc Psychiatry Psychiatr Epidemiol 2013;48:1519-26.

75. Mitchell MS, Goodman JM, Alter DA, et al. Development of the Health Incentive Program Questionnaire (HIP-Q) in a cardiac rehabilitation population. Trans/ Behav Med 2015;5:443-59.

76. Fernandez S, Olendzki B, Rosal MC. A dietary behaviors measure for use with low-income, Spanish-speaking Caribbean Latinos with type 2 diabetes: the Latino Dietary Behaviors Questionnaire. J Am Diet Assoc 2011;111:589-99.

77. Banna JC, Townsend MS. Assessing factorial and convergent validity and reliability of a food behaviour checklist for Spanishspeaking participants in US Department of Agriculture nutrition education programmes. Public Health Nutr 2011;14:1165-76.

78. Gans KM, Risica PM, Wylie-Rosett J, et al. Development and Evaluation of the Nutrition Component of the Rapid Eating and Activity Assessment for Patients (REAP): A New Tool for Primary Care Providers. J Nutr Educ Behav 2006;38:286-92.

79. Segal-Isaacson CJ, Wylie-Rosett J, Gans KM. Validation of a Short Dietary Assessment Questionnaire: The Rapid Eating and Activity Assessment for Participants Short Version (REAP-S). Diabetes Educ 2004;30:774-81.

80. Krabbenborg MA, Danner UN, Larsen JK, et al. The Eating Disorder Diagnostic Scale: psychometric features within a clinical population and a cut-off point to differentiate clinical patients from healthy controls. Eur Eat Disord Rev 2012;20:315-20.

81. Lee PH, Macfarlane DJ, Lam TH, et al. Validity of the international physical activity questionnaire short form (IPAQ-SF): A systematic review. Int J Behav Nutr Phys Act 2011;8:115

82. van der Ploeg HP, Tudor-Locke C, Marshall AL, et al. Reliability and validity of the international physical activity questionnaire for assessing walking. Res Q Exerc Sport 2010;81:97-101.

83. Evenson KR, Goto MM, Furberg RD. Systematic review of the validity and reliability of consumer-wearable activity trackers. Int Behav Nutr Phys Act 2015;12:159.

84. Reed JR, Struwe L, Bice MR, et al. The impact of self-monitoring food intake on motivation, physical activity and weight loss in rural adults. Appl Nurs Res 2017;35:36-41.

85. Krukowski RA, Harvey-Berino J, Bursac Z, et al. Patterns of success: Online self-monitoring in a web-based behavioral weight control program. Health Psychol 2013;32:164-70.

86. Painter SL, Ahmed R, Hill JO, et al. What Matters in Weight Loss? An In-Depth Analysis of Self-Monitoring. J Med Internet Res 2017;19:e160.

87. Ames GE, Heckman MG, Grothe KB, et al. Eating self-efficacy: Development of a short-form WEL. Eat Behav 2012;13:375-8.

88. Marcus BH, Selby VC, Niaura RS, et al. Self-Efficacy and the Stages of Exercise Behavior Change. Res Q Exerc Sport 1992;63:60-6.

89. Wilcox S, Castro CM, King AC. Outcome Expectations and Physical Activity Participation in Two Samples of Older Women. J Health Psychol 2006;11:65-77.

90. Leahey TM, LaRose JG, Lanoye A, et al. Secondary data analysis from a randomized trial examining the effects of small financial incentives on intrinsic and extrinsic motivation for weight loss. Health Psychol Behav Med 2017;5:129-44.

91. Wilson PM, Rodgers WM, Fraser SN. Examining the Psychometric Properties of the Behavioral Regulation in Exercise Questionnaire. Meas Phys Educ Exerc Sci 2002;6:1-21.

92. Center for Health Statistics N. NHANES 2015-2016 Medical Conditions Questionnaire. 2015.

93. CFPB Financial Well-Being Scale: Scale development technical report. In: Consumer Financial Protection Bureau 2017:1-54

94. Haisley E, Volpp KG, Pellathy T, et al. The impact of alternative incentive schemes on completion of health risk assessments. Am J Health Promot 2012;26:184-8.

95. Banerjee A, Duflo E, Goldberg N, et al. A multifaceted program causes lasting progress for the very poor: evidence from six countries. Science 2015;348:1260799.

96. Bradley KA, DeBenedetti AF, Volk RJ, et al. AUDIT-C as a brief screen for alcohol misuse in primary care. Alcohol Clin Exp Res 2007;31:1208-17.

97. Heatherton TF, Kozlowski LT, Frecker RC, et al. Measuring the heaviness of smoking: using self-reported time to the first cigarette 
of the day and number of cigarettes smoked per day. Br J Addict 1989;84:791-800.

98. Gold MR, Siegel JE, Russell LB, Weinstein MC, et al. eds. Costeffectiveness in health and medicine. New York, NY: Oxford University Press, 1996.

99. Occupational Employment Statistics. May 2014 National Occupational Employment and Wage Estimates United States. http://www.bls.gov/oes/current/oes_nat.htm

100. U.S. Bureau of Labor Statistics. Occupational Employment Statistics. Washington, DC: U.S. Department of Labor, Bureau of Labor Statistics, 2012.

101. Thomson Corporation. Red Book 2010: Pharmacy's Fundamental Reference. Montvale, NJ: Thomson PDR 2010.

102. Davidson KW, Bigger JT, Burg MM, et al. Stepped, Patient Preference-Based Treatment for Patients With Post-Acute Coronary Syndrome Depression: CODIACS Vanguard Randomized Controlled Trial. JAMA internal medicine 2013:1-8.

103. Ladapo JA, Bogart LM, Klein DJ, et al. Cost and Cost-Effectiveness of Students for Nutrition and eXercise (SNaX). Acad Pediatr. In Press. 2016;16.

104. Ladapo JA, Elliott MN, Bogart LM, et al. Cost of talking parents, healthy teens: a worksite-based intervention to promote parentadolescent sexual health communication. J Adolesc Health 2013;53:595-601.

105. Ladapo JA, Jaffer FA, Hoffmann U, et al. Clinical outcomes and cost-effectiveness of coronary computed tomography angiography in the evaluation of patients with chest pain. J Am Coll Cardiol 2009;54:2409-22.

106. Ladapo JA, Jaffer FA, Weinstein MC, et al. Projected costeffectiveness of smoking cessation interventions in patients hospitalized with myocardial infarction. Arch Intern Med 2011:171:39-45.

107. Ladapo JA, Shaffer JA, Fang Y, et al. Cost-effectiveness of enhanced depression care after acute coronary syndrome: results from the Coronary Psychosocial Evaluation Studies randomized controlled trial. Arch Intern Med 2012;172:1682-4.

108. Ladapo JA, Spritzer CE, Nguyen XV, et al. Economics of MR Operations After Implementation of Interpersonal Skills Training. J Am Coll Radiol 2018;15:1775-83.

109. Drummond MF. Methods for the economic evaluation of health care programmes. 3rd edn. Oxford; New York: Oxford University Press, 2005.

110. Panel on Cost-effectiveness in Health and Medicine US. Costeffectiveness in health and medicine: a report to the U. S. Public Health Service. Washington, DC: United States Public Health Service. Office of Disease Prevention and Health Promotion 1996.

111. Efron B. Better Bootstrap Confidence Intervals. J Am Stat Assoc 1987:82:171-85.

112. Chaudhary MA, Stearns SC. Estimating confidence intervals for cost-effectiveness ratios: an example from a randomized trial. Stat Med 1996;15:1447-58

113. Briggs $\mathrm{AH}$, Wonderling DE, Mooney CZ. Pulling cost-effectiveness analysis up by its bootstraps: a non-parametric approach to confidence interval estimation. Health Econ 1997;6:327-40.

114. Briggs AH, Mooney CZ, Wonderling DE. Constructing confidence intervals for cost-effectiveness ratios: an evaluation of parametric and non-parametric techniques using Monte Carlo simulation. Stat Med 1999;18:3245-62.

115. Campbell MK, Torgerson DJ. Bootstrapping: estimating confidence intervals for cost-effectiveness ratios. QJM 1999:92:177-82.

116. Shin DW, Yun JM, Shin JH, et al. Enhancing physical activity and reducing obesity through smartcare and financial incentives: A pilot randomized trial. Obesity 2017;25:302-10.

117. Finkelstein EA, Tham KW, Haaland BA, et al. Applying economic incentives to increase effectiveness of an outpatient weight loss program (TRIO) - A randomized controlled trial. Soc Sci Med 2017;185:63-70.

118. Ratliff JC, Palmese LB, Tonizzo KM, et al. Contingency management for the treatment of antipsychotic-induced weight gain: a randomized controlled pilot study. Obes Facts 2012;5:919-27.

119. Saccone AJ, Israel AC. Effects of experimenter versus significant other-controlled reinforcement and choice of target behavior on weight loss. Behav Ther 1978;9:271-8.

120. Mahoney MJ. Self-reward and self-monitoring techniques for weight control. Behav Ther 1974;5:48-57.

121. Kramer FM, Jeffery RW, Snell MK, et al. Maintenance of successful weight loss over 1 year: Effects of financial contracts for weight maintenance or participation in skills training. Behav Ther $1986 ; 17: 295-301$
122. Wing RR, Epstein LH, Marcus M, et al. Strong monetary contingencies for weight loss during treatment and maintenance. Behav Ther 1981;12:702-10.

123. VanEpps EM, Troxel AB, Villamil E, et al. Effect of Process- and Outcome-Based Financial Incentives on Weight Loss Among Prediabetic New York Medicaid Patients: A Randomized Clinical Trial. Am J Health Promot 2018:089011711878359.

124. Deci EL. Effects of externally mediated rewards on intrinsic motivation. J Pers Soc Psychol 1971;18:105-15.

125. Deci EL, Koestner R, Ryan RM. A meta-analytic review of experiments examining the effects of extrinsic rewards on intrinsic motivation. Psychol Bull 1999;125:627-68.

126. Promberger M, Marteau TM. When do financial incentives reduce intrinsic motivation? comparing behaviors studied in psychological and economic literatures. Health Psychol 2013;32:950-7.

127. Crane MM, Tate DF, Finkelstein EA, et al. Motivation for participating in a weight loss program and financial incentives: an analysis from a randomized trial. J Obes 2012;2012:1-9.

128. McDermott MM, Spring B, Berger JS, et al. Effect of a homebased exercise intervention of wearable technology and telephone coaching on walking performance in peripheral artery disease: The honor randomized clinical trial. JAMA 2018;319:1665-76.

129. Giuffrida A, Torgerson DJ. Should we pay the patient? Review of financial incentives to enhance patient compliance. BMJ 1997;315:703-7.

130. Banerjee AV, Hanna R, Kreindler GE, et al. Debunking the Stereotype of the Lazy Welfare Recipient: Evidence from Cash Transfer Programs. World Bank Res Obs 2017;32:155-84.

131. Park JD, Mitra N, Asch DA. Public opinion about financial incentives for smoking cessation. Prev Med 2012;55:S41-5.

132. Teixeira PJ, Carraça EV, Marques MM, et al. Successful behavior change in obesity interventions in adults: a systematic review of self-regulation mediators. BMC Med 2015;13:84.

133. Volpp KG, Troxel AB, Mehta SJ, et al. Effect of Electronic Reminders, Financial Incentives, and Social Support on Outcomes After Myocardial Infarction: The HeartStrong Randomized Clinical Trial. JAMA Intern Med 2017:177:1093-101.

134. Asch DA, Rosin R. Engineering Social Incentives for Health. N Engl $J$ Med 2016;375:2511-3.

135. Blondon KS. Patient attitudes about financial incentives for diabetes self-management: A survey. World J Diabetes 2015;6:752-8.

136. Chaiyachati KH, Asch DA, Grande DT. Patient Inducements - High Graft or High Value? N Engl J Med 2017;376:1107-9.

137. Schmidt $H$, Asch DA, Halpern SD. Fairness and wellness incentives: what is the relevance of the process-outcome distinction? Prev Med 2012;55:S118-23

138. Adams J, Giles EL, McColl E, et al. Carrots, sticks and health behaviours: a framework for documenting the complexity of financial incentive interventions to change health behaviours. Health Psychol Rev 2014;8:286-95.

139. Give it up for Baby. http://www.nhstayside.scot.nhs.uk/ OurServicesA-Z/MaternityServices/PROD_271552/index.htm

140. Ward K, Hull BP, Leask J. Financial incentives for childhood immunisation - a unique but changing Australian initiative. Med $\mathrm{J}$ Aust 2013;198:590-2.

141. The BMJ Opinion: Financial incentives for childhood immunisation in Australia. http://blogs.bmj.com/bmj/2015/05/07/financialincentives-for-childhood-immunisation-in-australia/

142. Volpp KG, Troxel AB, Pauly MV, et al. A randomized, controlled trial of financial incentives for smoking cessation. N Engl J Med 2009;360:699-709.

143. CVS to offer employees incentives to quit smoking. https://www. chaindrugreview.com/cvs-to-offer-employees-incentives-to-quitsmoking/

144. Volpp KG, Asch DA, Galvin R, et al. Redesigning employee health incentives-lessons from behavioral economics. N Engl J Med 2011:365:388-90

145. Wen X, Higgins ST, Xie C, et al. Improving Public Acceptability of Using Financial Incentives for Smoking Cessation During Pregnancy: A Randomized Controlled Experiment. Nicotine Tob Res 2016;18:913-8.

146. Promberger M, Brown RC, Ashcroft RE, et al. Acceptability of financial incentives to improve health outcomes in UK and US samples. J Med Ethics 2011;37:682-7.

147. Promberger M, Dolan P, Marteau TM. "Pay them if it works": discrete choice experiments on the acceptability of financial incentives to change health related behaviour. Soc Sci Med 2012;75:2509-14

148. Giles EL, Robalino S, Sniehotta FF, et al. Acceptability of financial incentives for encouraging uptake of healthy behaviours: A critical review using systematic methods. Prev Med 2015;73:145-58. 